\title{
$(4$ norden
}

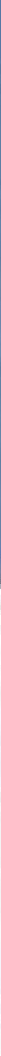

Sveriges ordförandeskap i

Nordiska ministerrådet 2013 


\section{Kultur och medier}

Program för Sveriges ordförandeskap i Nordiska ministerrådet 2013

ISBN 978-92-893-2511-0

http://dx.doi.org/10.6027/ANP2013-731

ANP2013:731

(C) Nordiska ministerrådet, Köpenhamn 2013

Design: Jette Koefoed/Nordiska ministerrådet

Fotos: ImageSelect

Upplaga: 500

Tryck: Rosendahls-Schultz Grafisk

Printed in Denmark

\section{Nordiska ministerrådet}

Ved Stranden 18

DK-1061 København K

Telefon (+45) 33960200

www.norden.org

\section{Det nordiska samarbetet}

Det nordiska samarbetet är ett av världens mest omfattande regionala samarbeten. Det omfattar Danmark, Finland, Island, Norge och Sverige samt Färöarna, Grönland och Åland.

Det nordiska samarbetet är politiskt, ekonomiskt och kulturellt förankrat och är en viktig partner i europeiskt och internationellt samarbete. Den nordiska gemenskapen arbetar för ett starkt Norden i ett starkt Europa.

Det nordiska samarbetet ska stärka nordiska och regionala intressen och värderingar i en global omvärld. Gemensamma värderingar länderna emellan bidrar till att stärka Nordens ställning som en av världens mest innovativa och konkurrenskraftiga regioner. 
IIIII norden 



\section{Q norden}

SEKTORPROGRAM

Kultur och medier

Program för Sveriges ordförandeskap

i Nordiska ministerrådet 2013 



\section{Förord}

Det nordiska kultursamarbetet utvecklas och fördjupas. De nordiska kulturministrarna har antagit en ny strategi för kultursamarbetet $2013-2020$. Som första ordförandeland kommer Sverige att genomföra aktiviteter som konkretiserar strategins fem teman: Det hållbara Norden, Det kreativa Norden, Det interkulturella Norden, Det unga Norden och Det digitala Norden.

Sverige har valt att lyfta fram barns och ungas rätt till kultur. Läsfrämjande för barn och unga samt frågor om mediekunnighet och den digitala tekniken är centrala. Här vet jag att det nordiska samarbetet har mycket att ge både i form av nya forskningsrön och genom konkret handling. Nordiska rådets nya pris för nordisk barn- och ungdomslitteratur utgör en viktig del i det lyft för barn- och ungdomslitteratur som de nordiska kulturministrarna beslutat om under det norska ordförandeskapet 2012.

Jag tror på potentialen i en nordisk, digital samverkan för kulturarvet. Jag vill också uppmärksamma kulturens betydelse för entreprenörskap, tillväxt och utveckling i Norden. Främjandet av de kulturella och kreativa näringarna bedrivs till betydande del genom att nordisk kultur- och näringspolitik samverkar. Min ambition är att det svenska ordförandeskapet på samma sätt kan bidra till att stärka sektorsövergripande nordiskt samarbete inom fler angelägna områden, såsom kultur och hälsa.
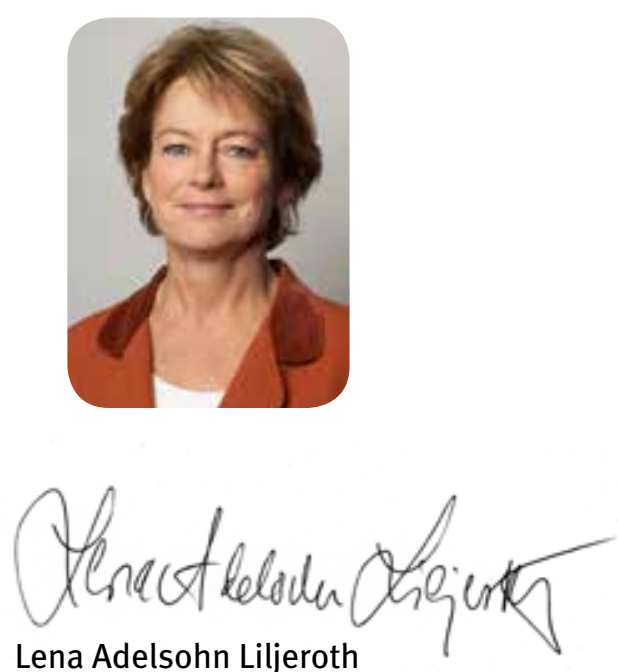

Kultur- och idrottsminister 


\section{Ny strategi för det nordiska kultursamarbetet 2013-2020}

\section{Kontinuitet och fokus}

Ministerrådet för kultur har beslutat om en långsiktig strategi för arbetet 2013-2020. Strategin blir ett gemensamt verktyg för kultursamarbetet i ett längre perspektiv och syftar till att ge samarbetet ännu tydligare kontinuitet och fokus. Målen i strategin ska avspeglas i målen för verksamheten vid de nordiska institutionerna, samarbetsorganen och programmen inom kultursamarbetet samt i en förstärkt dialog mellan de nordiska nationella kulturmyndigheterna.

På följande sidor beskrivs aktiviteterna under det svenska ordförandeskapet, ordnade under vart och ett av strategins fem teman: Det hållbara Norden, Det kreativa Norden, Det interkulturella Norden, Det unga Norden och Det digitala Norden.

Under ordförandeskapet anordnas aktiviteter som bland annat rör förmedling av kulturarv i det digitala Norden och främjande av de nordiska kulturella och kreativa näringarna samt konstnärernas villkor. Det svenska ordförandeskapet har valt att prioritera barns och ungas rätt till kultur under flera av strategins temaområden. 


\section{Ordförandeskapet om - det hållbara Norden}

Kulturens roll för hälsa och livskvalitet diskuteras alltmer. Omfattande forskning bedrivs i Norden och internationellt om kulturens roll när det gäller såväl förebyggande hälsovård som rehabiliteringsinsatser.

Klimatfrågan och politiken för ett långsiktigt hållbart samhälle har i dag blivit en central utgångspunkt för diskussioner om framtidens arkitektur och design. Arkitektur, form och design kan spela en viktig roll och belysa hur konstnärliga perspektiv och metoder kan förbättra livskvaliteten.

\section{Kultur och hälsa}

Utifrån ett svenskt initiativ bereds ett förslag inom det nordiska kultursamarbetet om att främja det utbyte om kultur och hälsa som redan etablerats i Norden. Sveriges ordförandeskap inriktas på att följa upp tidigare arbete och utveckla området kultur och hälsa på den nordiska dagordningen.

\section{Arkitektur, design och hållbarhet}

Flertalet nordiska länder har sedan 1990-talet antagit nationella handlingsprogram för arkitektur, form och design. De nordiska länderna har inspirerat varandra både i formuleringar och i genomförande av handlingsprogrammen.

Arkitektur, form och design är områden där de nordiska länderna har ett starkt internationellt anseende och goda exportmöjligheter. Ett nordiskt rundabordssamtal om hållbar arkitektur och design kommer att anordnas av Arkitekturmuseet. Mötet syftar till ett nordiskt utbyte om hur arkitektur och design kan bidra till ekonomisk, ekologisk, social och kulturell samhällsutveckling. 


\section{Ordförandeskapet om - det kreativa Norden}

De nordiska länderna satsar målmedvetet på att utveckla regionens kulturella och kreativa näringar för att ta tillvara kulturens betydelse och potential för entreprenörskap, tillväxt och utveckling. Kulturdriven tillväxt tillhör de områden som klättrar på den gemensamma nordiska agendan. Den tvärsektoriella samverkan som utvecklats de senaste åren mellan nordisk kulturoch näringspolitik, främst genom KreaNord, är av stor vikt för det fortsatta arbetet på nordisk nivå.

Goda villkor för konstnärer är avgörande för möjligheten att upprätthålla ett aktivt och professionellt konst- och kulturliv. Insatser för att vidga och stärka professionella kulturskapares arbetsmarknad är avgörande för att kunna öka möjligheterna för konstnärer och kulturskapare att försörja sig på sin konstnärliga eller kulturella yrkesverksamhet. Det är viktigt att politiken utvecklas i takt med den utveckling som sker i samhället, där de kulturella och kreativa näringarna får allt större utrymme.

\section{KreaNord}

KreaNord är Nordiska ministerrådets initiativ och plattform för att förbättra tillväxtmöjligheterna för regionens kulturella och kreativa näringar. I oktober 2013 planerar KreaNord att hålla en konferens i Sverige som särskilt riktar sig till organisationer och företrädare för de kulturella och kreativa näringarna.

\section{Nordisk samverkan kring konstnärernas villkor}

Konstnärsnämnden anordnar ett seminarium under 2013 med berörda myndigheter inom Norden. Seminariet ska belysa och jämföra konstnärernas situation i Nordens länder när det gäller statligt stöd samt ekonomiska och sociala villkor. Syftet är dels att ge ökad kunskap som kan ligga till grund för framtida beslut om konstnärspolitik i Norden, dels att skapa samverkan och nätverk kring dessa frågor på nordisk nivå. 


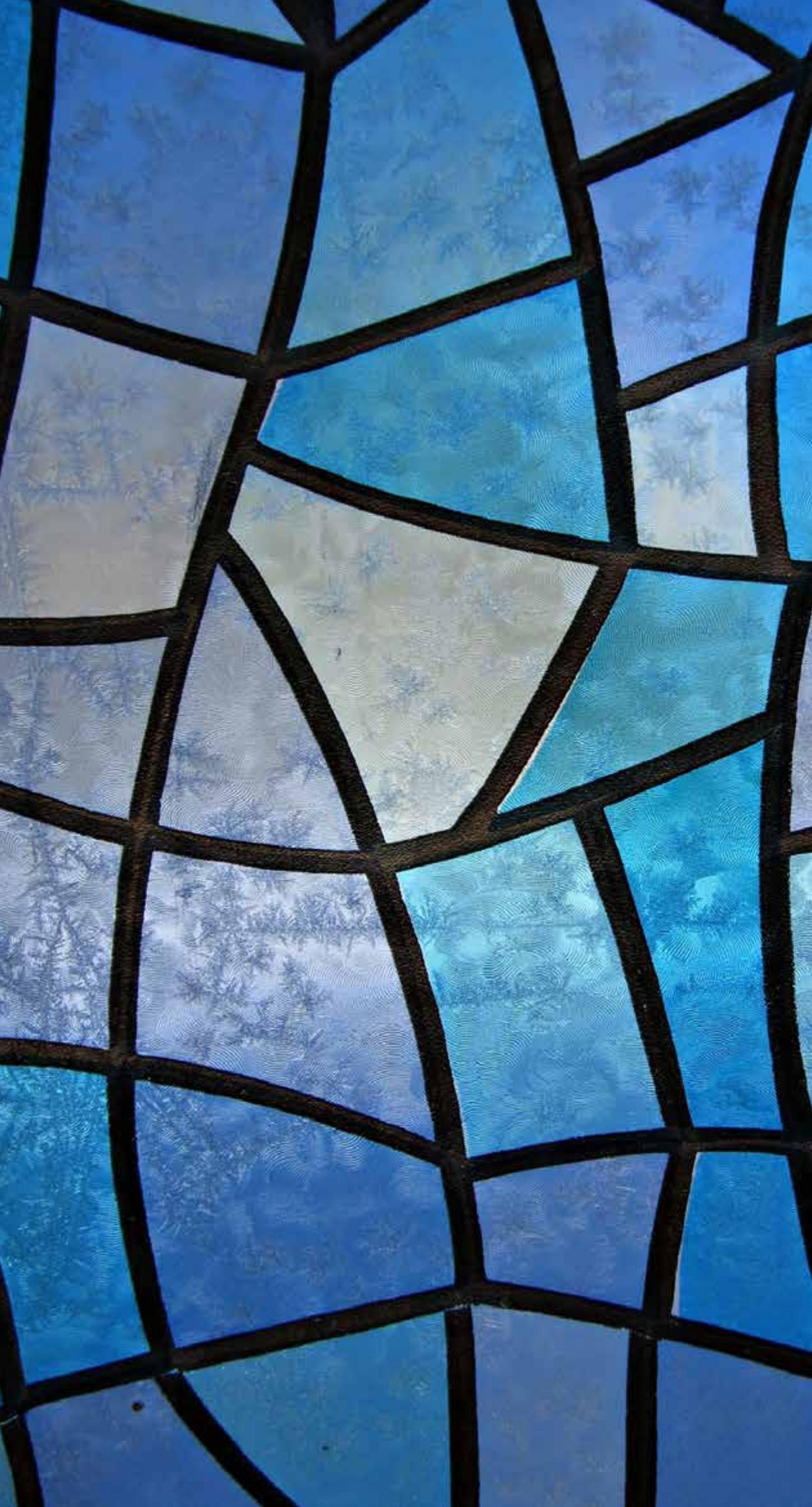





\section{Ordförandeskapet om - det interkulturella Norden}

Det nordiska kultursamarbetet ger stora möjligheter till möten och utbyte mellan kulturer. Vi som bor i Norden har i dag en kulturell tillhörighet som är mer mångfacetterad än tidigare, vilket ökar betydelsen av ett sådant utbyte. Den kulturella mångfalden är ett betydelsefullt element i det nordiska samarbetet. Strävan efter ett kulturellt inkluderande Norden bör därför genomsyra kultursamarbetet generellt, men också uppmärksammas särskilt. Vi vill främja yttrandefrihet och nordiska kärnvärden som miljö, jämställdhet och innovation både i vårt arbete inom Norden och när Norden möter kulturer utanför våra gränser.

\section{Fristäder för kulturutövare i ett nordiskt perspektiv}

Statens kulturråd anordnar ett nordiskt expertmöte om kulturella fristäder, med syfte att följa upp det nordiska kulturforum som arrangerades 2011 tillsammans med Svenska Akademien. Mötet är ett led i de nordiska kulturmyndigheternas samarbete i yttrandefrihetsfrågor. Fokus på expertmötet kommer att vara gemensamt erfarenhetsutbyte och möjligheterna att vidga fristadsarbetet mot andra konstarter än litteratur.

\section{Nordic Cool}

Nordisk kultur kommer att vara temat för den årliga internationella kulturfestivalen som pågår från den 19 februari till och med den 17 mars vid Kennedy Center i Washington, USA. Festivalen Nordic Cool synliggör Norden ur såväl kulturellt som politiskt perspektiv och blir därmed en värdefull plattform för det nordiska samarbetet och dess dialog med USA. Uppmärksamheten kring Norden skapar möjlighet till dialog om aktuella samhällsfrågor och den nordiska samhällsmodellen. Olika aspekter av den nordiska modellen kommer att presenteras genom seminarier och andra aktiviteter $i$ anslutning till kulturfestivalen. 


\section{Ordförandeskapet om - det unga Norden}

Barn och unga är en prioriterad målgrupp både i Nordiska ministerrådet och i de nordiska länderna. Inom ramen för det nordiska utbildnings- och forskningssamarbetet anordnas under året en konferens om ministerrådets nya organisering på språkområdet från och med 2014. Barn och unga är också $\mathrm{i}$ fokus under det svenska ordförandeskapet på kultur- och medieområdet.

På förslag av de nordiska kulturministrarna beslutade Nordiska rådet vid sin höstsession 2012 att instifta ett nordiskt barn- och ungdomslitteraturpris. Priset kommer att delas ut en gång per år och ges för ett litterärt verk, skrivet för barn och unga, på ett av de nordiska ländernas språk. Priset delas ut för första gången under 2013.

Barn- och ungdomslitteraturpriset ingår i ett lyft för nordisk barn- och ungdomslitteratur som också omfattar ökat översättarstöd, stöd till nätverk och till aktiviteter som direkt involverar barn och unga.

Sverige kommer att fortsatt driva arbetet med lyftet för nordisk barn- och ungdomslitteratur för att den ska nå fler läsare, både i och utanför Norden, och för att fler barn och unga i Norden ska lockas att läsa och skriva.

\section{Unga läsare i Norden}

De nordiska länderna har initierat olika projekt och verksamheter för att stärka barn- och ungdomskulturen, inte minst inom skolan. Sverige vill under ordförandeskapet fortsätta att stärka den gemensamma kompetensen på området. Under 2012 påbörjades en gemensam nordisk kartläggning över forskning om skolans samarbete med konstnärer. Resultaten kommer att presenteras under 2013.

Ungas läsförståelse sjunker i flera nordiska länder och Europa visar en nedåtgående trend vad gäller ungas läsvanor och läsförståelse. För att vända trenden är det viktigt att utbyta metodexempel, erfarenheter och forskningsresultat mellan de nordiska länderna. Statens kulturråd anordnar en konferens om litteratur och läsfrämjande, med fokus både på insatser i skolan och på barns och ungas läsning på fritiden. Konferensen arrangeras i samarbete med Lunds universitet och riktar sig till forskare, myndigheter och organisationer som arbetar med litteratur- och läsfrämjande samt till företrädare för skolsektorn. 



\section{Ordförandeskapet om - det digitala Norden}

Yttrandefrihet och fria medier utgör två av demokratins stöttepelare. Med den digitala utvecklingen har villkoren för att delta i samhället förändrats $i$ grunden. Nya kanaler för delaktighet i samhället och debatten ger ständigt nya möjligheter men kräver också allt större kunskap. Likaså krävs ett kritiskt förhållningssätt för att orientera sig i det stora medieutbudet. I dag talar vi om mediekunnighet i nästan samma termer som vi talar om läskunnighet.

Barn och unga tillhör den grupp som exponeras mest för nya medier, men är också den grupp som har mest medievana. Den gemensamma synen på demokrati, samhälle och på barn och unga ger särskilt goda förutsättningar för arbetet med mediekunnighet på nordisk nivå.

Det finns fortfarande begränsningar i möjligheterna för nordbor att ta del av sina nordiska grannars kultur och verkligheter. Skälen är geografiska såväl som organisatoriska och tekniska. Det handlar om bättre tillgång till och större spridning av nordisk kultur i radio och tv, men också om kulturen som återfinns på museer och i arkiv. Den ökande digitaliseringen skapar bättre möjligheter för många att ta del av det nordiska kulturutbudet och ökar möjligheterna för en bredare kulturgemenskap.

\section{Mediekunnighet och yttrandefrihet}

Ett expertmöte om mediekunnighet som nyckel till yttrandefrihet och demokrati kommer att anordnas i Stockholm av Statens medieråd och det nordiska informationscentret för medie- och kommunikationsforskning Nordicom. Syftet är att skapa ett nätverk av berörda myndigheter i varje nordiskt land och berörda organ i det nordiska samarbetet kring mediekunnighet. En nordisk plattform har goda möjligheter att skapa förutsättningar för en fruktbar växelverkan mellan den nationella och den nordiska nivån. Detta kan även på sikt bidra till dialogen på europeiskt och globalt plan.

\section{Kulturarvet i det digitala Norden - utveckling för tillgänglighet}

Kulturarvet i de nordiska länderna har genom historien vävt samman händelser, individer och kulturella processer och tagit sig uttryck i ett materiellt och immateriellt kulturarv. Mängden digital information växer och tillgängliggörs genom nationella söktjänster och portaler, samt genom det europeiska digitala biblioteket Europeana. Det finns en stor potential i att länka samman 
information från källor i olika länder. Sådan länkning gör det möjligt att belysa historiska samband i Norden och lägga grunden för fördjupad förståelse, upplevelser, kunskapsbygge och tillväxt.

En nordisk konferens kommer att anordnas av Digisam, det nationella sekretariatet för digitalisering, digitalt bevarande och digitalt tillgängliggörande av kulturarvet. Konferensen kommer att ta upp potentialen i en nordisk samverkan inom produktion och användning av digital kulturarvsinformation. Temat för konferensen inriktas på betydelsen av "öppen data" och syftar till att belysa möjligheterna till långsiktig nordisk samverkan. En utvecklad samverkan kan även stärka det gemensamma åtagandet i Europeana.

\section{Konsolidering och uppföljning}

En förutsättning för ett vitalt nordiskt samarbete i en tid av stora omvärldsförändringar är att vi ständigt är beredda att se över våra samarbetsformer. Det nordiska samarbetet har successivt reformerats under senare år och alla ministerråd har uppgiften att på sina respektive områden kontinuerligt överväga förändringar av samarbetet. Samarbetet på kultur- och medieområdet har effektiviserats genom en rad reformer. Under det svenska ordförandeskapet kommer reformarbetet att konsolideras och följas upp.

\section{Kulturforum}

Inom ramen för det nordiska kultursamarbetet anordnas sedan 2012 ett årligt kulturforum, som en plattform för en kontinuerlig nordisk kulturpolitisk diskussion. Fokus för 2012 års kulturforum var inriktningen på den nya strategin för det nordiska kultursamarbetet 2013-2020.

Kulturforum 2013 kommer att behandla frågor om implementering av strategin. Av central betydelse i sammanhanget är våra nordiska institutioner och samarbetsorgan. Temana i den nya strategin ska på olika sätt genomsyra deras verksamheter. 


\section{Preliminärt kalendarium 2013}

\begin{tabular}{|c|c|c|}
\hline Datum & Möte & Plats \\
\hline 7-8 februari & Ämbetsmannakommittémöte & Köpenhamn \\
\hline 19 februari & Informellt kulturministermöte & Washington \\
\hline 19 februari-17 mars & Nordic Cool, kulturfestival & Washington \\
\hline $21-22$ mars & Ämbetsmannakommittémöte & Stockholm \\
\hline 23 april & Kulturministermöte & Stockholm \\
\hline $24-25$ april & $\begin{array}{l}\text { Öppna data - om digitalisering, } \\
\text { digitalt bevarande och digitalt } \\
\text { tillgängliggörande av kulturarvet, } \\
\text { konferens av Digisam }\end{array}$ & Malmö \\
\hline Juni & Kulturforum & Köpenhamn \\
\hline 19-20 september & Ämbetsmannakommittémöte & \\
\hline Oktober & $\begin{array}{l}\text { En nordisk jämförelse av villkor för } \\
\text { konstnärligt skapande - om statligt stöd } \\
\text { och trygghetssystem, konferens av } \\
\text { Konstnärsnämnden }\end{array}$ & Stockholm \\
\hline Oktober & $\begin{array}{l}\text { Från särintresse till allmänintresse } \\
\text { - nordens kulturella och kreativa } \\
\text { näringar tar plats! Konferens av KreaNord }\end{array}$ & \\
\hline 2 oktober & $\begin{array}{l}\text { Mediekunnighet som nyckeln } \\
\text { till yttrandefrihet och demokrati, } \\
\text { konferens av Statens medieråd }\end{array}$ & Stockholm \\
\hline 24-25 oktober & $\begin{array}{l}\text { Unga läsare i Norden, } \\
\text { konferens av Statens kulturråd }\end{array}$ & Lund \\
\hline 30 oktober & Kulturministermöte & Oslo \\
\hline 11-12 november & $\begin{array}{l}\text { Nordiska fristäder för konstnärlig } \\
\text { yttrandefrihet, konferens av } \\
\text { Statens kulturråd }\end{array}$ & Umeå \\
\hline 15 november & $\begin{array}{l}\text { Nordisk arkitektur och design - } \\
\text { tillgänglig, barnanpassad och } \\
\text { hållbar - se'n då? Konferens av } \\
\text { Arkitekturmuseet }\end{array}$ & Stockholm \\
\hline 4-5 december & Ämbetsmannakommittémöte & Köpenhamn \\
\hline
\end{tabular}





\section{norden}

Nordiska ministerrådet

Ved Stranden 18

DK-1061 København K

www.norden.org

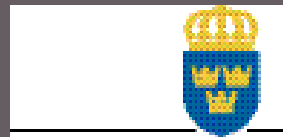

REGERINGSKANSLIET

\section{Kulturdepartementet}

Ytterligare information om Sveriges ordförandeskap i

Nordiska ministerrådet fås på www.regeringen.se/norden 2013

Kontaktuppgifter för ordförandeskapet

Kulturdepartementet

SE-103 33 Stockholm

Sverige

Telefon (växel):

+4684051000 